\title{
ANÁLISE DE AVALIAÇÕES APLICADAS EM UMA LICENCIATURA EM CIÊNCIAS BIOLÓGICAS: EM BUSCA DE (RES)SIGNIFICAÇÕES
}

\section{ANALYSIS OF EVALUATIONS APPLIED IN A BACHELOR IN BIOLOGICAL SCIENCES: IN SEARCH OF (RE) SIGNIFICATIONS}

\author{
Marcos Fernandes-Sobrinho ${ }^{1}$ \\ Tiago Clarimundo Ramos ${ }^{2}$ \\ Arthur Pires da Silva ${ }^{3}$ \\ Ivandilson Pessoa Pinto de Menezes ${ }^{4}$ \\ Paula Silva Resende Fernandes 5 \\ Paulo Alexandre de Castro ${ }^{6}$ \\ Guilherme Malafaia $^{7}$
}

\begin{abstract}
Resumo: Foram analisadas 100 avaliações escritas (AE) relacionadas ao ensino de conceitos de Biologia, elaboradas e aplicadas por professores atuantes em uma Licenciatura em Ciências Biológicas de uma instituição pública de ensino superior, da região Centro-Oeste, no Brasil, no período de 2011 a 2014. Para validação, e posterior análise quali-quantitativa das $\mathrm{AE}$, contamos com dois docentes especialistas na área. A dissimilaridade entre as $\mathrm{AE}$ analisadas foi estimada com base no coeficiente de Jaccard, e na sequência foi construído um correspondente dendrograma, dos dados gerados e categorizados. Os resultados obtidos sinalizam, que entre os agrupamentos de categorias hierárquicas houve a predominância de perfil tradicional de avaliação com forte apelo ao conhecimento enciclopédico e memorístico. Verificou-se também AE que possibilitavam explorar habilidades cognitivas dos estudantes e aspectos mais abrangentes, em contraposição à aprendizagem mecânica do conhecimento científico. Por fim, o estudo sugere haver necessidade de repensar caminhos alternativos aos modelos de avaliação tradicionais.
\end{abstract}

\footnotetext{
${ }^{1}$ Doutor em Educação em Ciências e Matemática/Universidade de Brasília (PPGE/FE/UnB). Professor permanente da área de Física; credenciado junto ao Programa de Pós-Graduação em Educação Profissional Tecnológica do Instituto Federal Goiano (ProfEPT/IFGoiano), Urutaí, Goiás, e ao Programa de PósGraduação em Gestão Organizacional da Universidade Federal de Catalão (PPGGO/UFCat), Catalão, Goiás, Brasil. E-mail: marcos.fernandes@ifgoiano.edu.br

${ }^{2}$ Doutor em Educação em Ciências e Matemática pela Universidade de Brasília (PPGE/FE/UnB). Professor da área de Física do Instituto Federal Goiano (IFGoiano), Rio Verde, Goiás, Brasil. E-mail: tiago.ramos@ifgoiano.edu.br

${ }^{3}$ Licenciado em Ciências Biológicas, Instituto Federal Goiano (IFGoiano), Urutaí, Goiás, Brasil. E-mail: arthurp.sillvaa@gmail.com

${ }^{4}$ Doutor em Genética e Biologia Molecular pela Universidade Estadual de Santa Cruz (UESC). Professor permanente da área de Ciências Biológicas e do Programa de Pós-Graduação em Conservação de Recursos Naturais do Cerradodo do Instituto Federal Goiano (PPGCReNaC/IFGoiano), Urutaí, Goiás, Brasil. E-mail: ivan.menezes@ifgoiano.edu.br

${ }^{5}$ Mestrado em Linguística Aplicada pela Universidade de Brasília (UnB). Professora da área de Línguística do Instituto Federal Goiano (IFGoiano), Urutaí, Goiás, Brasil. E-mail: paula.silva@ifgoiano.edu.br

${ }^{6}$ Doutor em Física Básica pela Universidade de São Paulo/Instituto de Física de São Carlos (USP/IFSC). Professor Associado I da Universidade Federal de Catalão (UFCat), credenciado junto ao Programa de PósGraduação em Gestão Organizacional (PPGGO/UFCat), Catalão, Goiás, Brasil. E-mail: padecastro@gmail.com

${ }^{7}$ Doutor em Agronomia/Universidade Federal de Goiás (UFG). Professor permanente da área de Ciências Biológicas e do Programa de Pós-Graduação em Conservação de Recursos Naturais do Cerrado do Instituto Federal Goiano (PPGCReNaC/IFGoiano) Urutaí, Goiás, Brasil. E-mail: guilhermeifgoiano@gmail.com
} 
Palavras-chave: Educação em ciências; Avaliação da aprendizagem; Avaliação da ensinagem; Ensino de biologia.

\begin{abstract}
We analyzed 100 written evaluations related to the teaching of Biology concepts, elaborated and applied by professors working in a Biological Sciences Degree from a public higher education institution, from the Center-West region of Brazil, between 2011 to 2014. For validation, and subsequent qualitative-quantitative analysis of the $\mathrm{AE}$, we counted with two specialists. The dissimilarity between the EA analyzed was estimated based on the Jaccard coefficient, and following a corresponding dendrogram was constructed, of the data generated and categorized. The results obtained indicate that among the groupings of hierarchical categories there was a predominance of a traditional evaluation profile with strong appeal to the encyclopedic and memory knowledge. Was also verified AE that made it possible to explore students' cognitive abilities and broader aspects, as opposed to the mechanical learning of scientific knowledge. Finally, the study suggests that there is a need to rethink alternative paths to traditional evaluation models.
\end{abstract}

Keywords: Education in sciences; Learning assessment; Teaching assessment; Teaching of biology.

\title{
1 Introdução
}

As avaliações, seja a educacional ou a de aprendizagem são temas de extrema importância da área de Educação, e que ainda têm muito à serem explorados/estudados, e que guardam estreita relação com dimensões políticas, sociais, além de dimensões referentes a estrutura educacional como trabalho pedagógico, a organização e a disseminação do conhecimento, bem como de seus resultados (FERNANDESSOBRINHO et al., 2017). Segundo Santiago (2006), as avaliações educacionais são processos que buscam: a) conhecer a produção das intenções socioeducativas; b) acompanhar a concretização dessas ideias, e; c) analisar as bases e os modos em que as práticas pedagógicas escolares ocorrem e em que resultam.

Quanto a forma e concepção, as avaliações possuem potencial extremamente de diversificação. São muitos os autores que tratam desse tema, e há um consenso quanto a possibilidade de classificar as avaliações em três concepções (grupos) (GUERRA, 1993; SANT'ANNA, 2014): 1) diagnóstica; 2) formativa e; 3) classificatória (ou somatória). Tais concepções de avaliação estão diretamente ligadas às funções e objetivos do processo de ensino-aprendizagem, como veremos a seguir:

1) A avaliação diagnóstica pode ser entendida como aquela que é aplicada no início do processo de ensino-aprendizagem, por isso também pode ser chamada de preditiva (COLL; MARTÍN; ONRUBIA, 2004). Ao aplicar a avaliação diagnóstica, antes de iniciar uma unidade de ensino ou um determinado assunto/tema/conteúdo, o(a) professor(a) tem a oportunidade de fazer uma verificação/apreciação dos conhecimentos prévios dos alunos, para só então, planejar e consolidar seus métodos e estratégias de 
ensino. Lembrando que “... a finalidade é que o professor inicie o processo educacional com um conhecimento real das características de seus alunos, tanto no plano pessoal quanto no acadêmico" (ARREDONDO; DIAGO, 2009 p. 62).

2) A avaliação formativa pode começar com uma a avaliação diagnóstica, pois esse tipo de avaliação pressupõe que ao conhecer os resultados do ensino, o professor reflita se houve ou não aprendizagem e desenvolvimento cognitivo planejado. A partir daí, é possível planejar novamente as suas atividades de ensino, visando complementação e correção dos erros que por ventura aconteçam ao logo do processo. Neste caso, há um retorno do professor para sua prática e reformulação para aperfeiçoamento da aprendizagem. Para Haydt (2008, p. 18),

a avaliação formativa está muito ligada ao mecanismo de feedback ... É por esta razão que os especialistas afirmam ser essa modalidade de avaliação uma parte integrante do processo ensino-aprendizagem e, quando bem realizada, assegura que a maioria dos alunos alcance o objetivo desejado.

Vale registrar que a proposta da avaliação formativa é se concentrar no processo didático e não nos resultados. Desse modo, na avaliação formativa visualizamos a avaliação não como um objetivo fim, mas como uma parte do processo ensinoaprendizagem experimentado/vivenciado tanto por professores como pelos alunos.

3) A avaliação classificatória (ou somatória) é um modelo que favorece o autoritarismo, e que tem como objetivo/função principal verificação do aprendizado, medindo e consequentemente classificando os alunos conforme os seus desempenhos nas aplicações dos instrumentos avaliativos. Essa avaliação usualmente ocorre no final de um curso, unidade de ensino ou tema/assunto/conteúdo (HAYDT, 2008). Dessa forma, a avaliação classificatória considera os alunos segundo o seu rendimento escolar, procurando um resultado coletivo igualitário entre eles e não tem como objetivo propor modificar/melhorar o processo de ensinoaprendizagem dos alunos, pois ela finaliza/encerra o processo de ensino.

Perrenoud (1999, p. 18) afirma que a "avaliação tradicional, não satisfeita em criar fracasso, empobrece as aprendizagens e induz, nos professores, didáticas conservadoras e, nos alunos, estratégias utilitaristas”. Surgindo então a importância e necessidade da implantação da avaliação formativa, que objetiva encontrar alternativas diferentes para o 
processo educativo, como por exemplo, metodologias diversas que visem melhorar o ensino.

Nessa linha de pensamento, as avaliações formativas vêm alume para fazer frente à avaliação tradicionalista em um processo de resiliência, que busca acabar com o mito de avaliação como punição e levá-la a ser uma interação professor-aluno. A avaliação formativa, dentro da pedagogia formativa, é uma tentativa de se conseguir abrir novos caminhos para a educação (GARUTTI, 2010).

Campos, Gomes e Furtado (2012), afirmam que, em se tratando de avaliação, fazse necessário pensar em uma ação avaliativa com a finalidade de acompanhar o dia-a-dia do processo de aprendizagem. A esse respeito, Hoffmann (2014) comenta que, a avaliação mediadora é um processo que necessita da interação, o diálogo, e do espaço de encontro e de dissonância de ideias entre o educador e educando, em busca de patamares qualitativos do conhecimento, representando assim uma das várias funções da avaliação no espaço educacional.

Diante do exposto, nos parece adequado utilizar as noções defendidas por Luckesi (2014), que afirma que a prática de avaliação escolar contemporânea não deve mostra-se excessivamente autoritária. Para o autor, esse tipo de ação avaliadora apresenta-se demasiadamente selecionadora tornando-se desnecessária no processo educacional. Em contrapartida, a discussão da construção de modelos para redefinição do cotidiano escolar, caracteriza-se urgente e necessária, já que, a avaliação é uma questão fundamental no processo do ensino-aprendizagem.

Nesse sentido, a análise dos instrumentos usados na avaliação da aprendizagem, em um contexto sistemático e abrangente se faz necessário, de modo a instigar reflexões sobre a necessidade de evitarmos que o método avaliativo se restrinja apenas à classificação dos estudantes. A partir dessas análises é possível refletir, ainda, além da prática avaliativa docente, a significância do significado acerca da avaliação da aprendizagem.

Assim sendo, neste artigo, após a análise de 100 avaliações escritas (AE) relacionadas ao ensino de conceitos de Biologia - elaboradas e aplicadas por professores atuantes em um curso de Licenciatura em Ciências Biológicas de uma instituição pública de ensino superior, da região Centro-Oeste, no Brasil, no período de 2011 a 2014 propusemos possíveis agrupamentos de categorias hierárquicas quanto aos diferentes perfis identificados. Realizamos, por fim, reflexões acerca dos aspectos positivos e 
negativos dos instrumentos avaliativos analisados e suas relações com o processo de formação inicial de professores.

\section{Material e métodos}

Objeto de análise documental, para o presente artigo, foi constituído da seleção aleatória de $100 \mathrm{AE}$ dentro do escopo de disciplinas relacionadas ao ensino de conceitos de Biologia, aplicadas em diferentes turmas e períodos de um curso de Licenciatura em Ciências Biológicas de uma instituição pública de ensino superior, da região CentroOeste, no Brasil, no período de 2011 a 2014. A validação do estudo se deu por meio de análise quali-quantitativa dessas $\mathrm{AE}$, envolvendo dois docentes especialistas na área. $\mathrm{O}$ acesso e a coleta das AE, para fins de análise, deram-se por meio de professores [elaboradores e aplicadores daquelas AE] e de estudantes do curso, pelo fato de, em geral, colecionarem as AE de interesse, neste trabalho. A Tabela 1 apresenta o total de $100 \mathrm{AE}$, distribuído entre as disciplinas que envolvem conceitos de Biologia e que estão presentes no referido curso.

Tabela 1: Quantidade de AE por disciplina no âmbito da amostra selecionada

\begin{tabular}{cc}
\hline Disciplinas & Quantidade de AE \\
Biologia Celular & 18 \\
Biologia das Criptógamas & 4 \\
Organografia Vegetal & 2 \\
Anatomia Vegetal & 1 \\
Morfologia Vegetal & 4 \\
Zoologia dos Invertebrados I & 4 \\
Ecologia & 5 \\
Zoologia dos Invertebrados II & 3 \\
Sistemática Vegetal & 3 \\
Bioquímica & 3 \\
Histologia & 4 \\
Embriologia & 2 \\
Zoologia dos Vertebrados & 7 \\
Fisiologia Vegetal & 4 \\
Microbiologia Geral & 2 \\
Genética & 4 \\
\hline Comparada dos Vertebrados & 3 \\
\hline
\end{tabular}




\begin{tabular}{cc}
\hline Ecologia de Populações e Comunidades & 2 \\
Geologia e Paleontologia & 2 \\
Fisiologia Animal Comparada & 1 \\
Biologia Molecular & 4 \\
Evolução & 2 \\
Parasitologia Humana & 8 \\
Imunologia Básica & 2 \\
Total & $\mathbf{1 0 0}$ \\
\hline
\end{tabular}

Fonte: Elaborado pelos autores.

Cada AE foi catalogada e analisada por dois avaliadores independentes, e para isso foi construído um roteiro de avaliação (Quadro 1), que foi elaborado com base na literatura científica relacionada à área foco deste estudo. Quando a avaliação das AE apresentava divergência entre os avaliadores, estes discutiam a respeito até atingirem consenso. Salienta-se que a avaliação de cada AE, de modo geral, abrangia número de questões dos tipos objetivas e discursas; se havia questões meramente conteudistas [conteúdo pelo conteúdo apenas]; com apelo à memorização; se trabalhavam questões reais do cotidiano dos estudantes; se exigia domínio de linguagem; compreensão de algum fenômeno; e também como eram classificadas, podendo ser do tipo: síntese; análise; reconhecimento; julgamento; compreensão; aplicação, entre outros. Os nomes dos professores regentes, quando identificados, foram codificados de sorte a torná-los anônimos aos leitores deste artigo.

\begin{tabular}{|c|c|}
\hline \multicolumn{2}{|c|}{ Curso e turma (série ou período) em que a prova foi aplicada: } \\
\hline Disciplina: & \multirow[t]{2}{*}{ Professor regente: } \\
\hline Ano e semestre de aplicação: & \\
\hline $\begin{array}{l}\text { A prova tem um espaço adequado para a } \\
\text { identificação do estudante? } \\
\text { ( ) Sim } \\
\text { ( ) Não }\end{array}$ & $\begin{array}{l}\text { O valor da prova é explícito em seu cabeçalho? } \\
\text { ( ) Sim } \\
\text { ( ) Não }\end{array}$ \\
\hline $\begin{array}{l}\text { A prova contém orientações gerais claras e } \\
\text { suficientes para os estudantes resolvê-la? } \\
\text { ( ) Sim } \\
\text { ( ) Não }\end{array}$ & Qual o número de questões da prova? \\
\hline Critérios de avaliação & Identificação da questão \\
\hline $\begin{array}{l}\text { As questões apresentam erros na língua } \\
\text { portuguesa? }\end{array}$ & \\
\hline
\end{tabular}




\begin{tabular}{|c|c|}
\hline Existem questões são do tipo “objetiva"? & \\
\hline Quais questões são do tipo "discursiva"? & \\
\hline Existem questões são do tipo "autoavaliação"? & \\
\hline Existem questões são do tipo "memorização"? & \\
\hline $\begin{array}{l}\text { Existem questões em que se observa a } \\
\text { colocação de textos que exijam a leitura, } \\
\text { mesmo curta, e que provoquem respostas } \\
\text { argumentativas? }\end{array}$ & \\
\hline $\begin{array}{l}\text { Existem questões que trabalham o conteúdo } \\
\text { em contextos e situação reais ou similares aos } \\
\text { que o estudante pode encontrar na vida real? }\end{array}$ & \\
\hline $\begin{array}{l}\text { Existem questões despertem o espírito crítico } \\
\text { do estudante e avaliem habilidades como } \\
\text { comparar, interpretar e relacionar? }\end{array}$ & \\
\hline $\begin{array}{l}\text { Existem questões utilizam termos } \\
\text { considerados subjetivos (que dificultam a } \\
\text { avaliação da aprendizagem), como "cite } \\
\text { exemplos", "na sua opinião", "comente" etc.? }\end{array}$ & \\
\hline Existem questões exigem do estudante: & \\
\hline a) Domínio de linguagem & \\
\hline b) Compreensão de fenômenos & \\
\hline c) Enfrentamento de problemas & \\
\hline d) Construção da argumentação & \\
\hline e) Elaboração de propostas & \\
\hline $\begin{array}{l}\text { Existem questões que expõem os estudantes } \\
\text { ao ridículo? Anotar exemplo(s) de } \\
\text { questão(ões) dessa natureza. }\end{array}$ & \\
\hline $\begin{array}{l}\text { Existem questões são do tipo “pegadinha” ou } \\
\text { “armadilha”? Anotar exemplo(s) de } \\
\text { questão(ões) dessa natureza. }\end{array}$ & \\
\hline $\begin{array}{l}\text { Existem questões que utilizam elementos } \\
\text { gráficos (tabelas, quadros, esquemas, imagens, } \\
\text { figuras, etc.)? }\end{array}$ & \\
\hline $\begin{array}{l}\text { Existem questões em que esses elementos } \\
\text { gráficos são de qualidade (avaliar: escala, } \\
\text { clareza, nitidez, coerência com a questão, } \\
\text { etc.)? }\end{array}$ & \\
\hline
\end{tabular}




\begin{tabular}{|l|l|}
\hline $\begin{array}{l}\text { Existem questões no enunciado das perguntas } \\
\text { que NÃO explicita claramente o que os } \\
\text { estudantes precisam fazer ou responder? }\end{array}$ & \\
\hline Existem questões do tipo "análise”? & \\
\hline Existem questões do tipo "síntese"? & \\
\hline $\begin{array}{l}\text { Existem questões do tipo "julgamento" ou } \\
\text { "avaliação"? }\end{array}$ & \\
\hline Existem questões do tipo "reconhecimento"? & \\
\hline Existem questões do tipo “compreensão"? & \\
\hline Existem questões do tipo "aplicação"? & \\
\hline
\end{tabular}

Quadro 1: Roteiro de avaliação da AE selecionadas

Fonte: Adaptado de: SANT'ANNA (2014), LUCKESI (2014) e GUERRA (1993)

No Quadro 2, com o propósito de servir como espécie de glossário, são apresentados os conceitos e (ou) noções de termos presentes no formulário de avaliação das AE foi construído, partindo do pressuposto de que determinados termos presentes no roteiro de avaliação (Quadro 1) proposto são potencialmente subjetivos.

\begin{tabular}{|c|c|}
\hline Termos & Conceitos/noções presentes no roteiro de avaliação \\
\hline Questões do tipo discursiva & $\begin{array}{l}\text { Foram aquelas que exigiram do aluno respostas estruturadas } \\
\text { com suas próprias palavras, baseadas na norma padrão da } \\
\text { língua materna. }\end{array}$ \\
\hline Questões do tipo autoavaliação & $\begin{array}{l}\text { Foram aquelas que possibilita o aluno se autoavaliar, } \\
\text { permitindo o estudante influenciar ou participar de sua } \\
\text { própria avaliação. }\end{array}$ \\
\hline Questões do tipo "decoreba" & $\begin{array}{l}\text { Foram aquelas que exigiram do aluno menos raciocínio e } \\
\text { capacidade mental, elas apenas requereram memorização de } \\
\text { conceitos e fórmulas. }\end{array}$ \\
\hline $\begin{array}{l}\text { Questões que expõem os estudantes ao } \\
\text { ridículo }\end{array}$ & $\begin{array}{l}\text { Foram aquelas que deixaram os alunos constrangidos, } \\
\text { intimidados ou até mesmo expunham particularidades dos } \\
\text { alunos. }\end{array}$ \\
\hline $\begin{array}{l}\text { Questões do tipo "pegadinha" ou } \\
\text { "armadinha" }\end{array}$ & $\begin{array}{l}\text { Foram aquelas que não diziam exatamente o que aluno } \\
\text { deveria redigir, ou também aquelas questões que os deixam } \\
\text { confuso quanto à resposta. }\end{array}$ \\
\hline Questões do tipo análise & $\begin{array}{l}\text { Enquadrou-se em questão que parte de um todo para } \\
\text { compreensão minuciosa de suas partes, pode ser aplicada por } \\
\text { exemplo, em análise de charges ou gráficos. }\end{array}$ \\
\hline Questões do tipo síntese & $\begin{array}{l}\text { É o inverso da análise, relaciona diversas partes para } \\
\text { estabelecer as características de um todo, fazendo assim uma } \\
\text { descrição abreviada de um texto, por exemplo. }\end{array}$ \\
\hline $\begin{array}{l}\text { Questões do tipo julgamento ou } \\
\text { avaliação }\end{array}$ & $\begin{array}{l}\text { Exigiu do aluno maior de conhecimento de conteúdo, } \\
\text { contendo nível de maior complexidade. Há emissão de juízo } \\
\text { de valor, havendo necessidade de apresentar justificativas ou } \\
\text { argumentos. }\end{array}$ \\
\hline Questões do tipo reconhecimento & $\begin{array}{l}\text { Dentro os tipos de questões presente nas avaliações, esta } \\
\text { exigiu menor complexidade. Baseia-se na identificação das } \\
\text { propriedades fundamentais dos objetos, elas se caracterizam } \\
\text { por nomear, citar, assinalar, identificar, por exemplo. }\end{array}$ \\
\hline
\end{tabular}




\begin{tabular}{|l|l|}
\hline Questões do tipo compreensão & $\begin{array}{l}\text { Neste tipo além da identificação, existiu a indicação de } \\
\text { elementos que dão significado ao objeto. Podendo conter no } \\
\text { enunciado palavras como apresente características, dê } \\
\text { significados. }\end{array}$ \\
\hline \multirow{2}{*}{ Questões do tipo aplicação } & $\begin{array}{l}\text { É caracterizada pela transposição da compreensão de um } \\
\text { objeto de conhecimento. Quando compreendida alguma } \\
\text { fórmula ou conceito eles são aplicados em situações e em } \\
\text { problemas semelhantes. Há uma situação-problema com } \\
\text { parâmetros bem definidos e uma sequência lógica a ser } \\
\text { seguida, caracterizada no enunciado por exemplo, com base } \\
\text { no texto. }\end{array}$ \\
\hline
\end{tabular}

Quadro 2: Conceitos e(ou) noções de termos presentes no formulário de avaliação

Fonte: Adaptado de: SANT'ANNA (2014), LUCKESI (2014) e GUERRA (1993)

Visando avaliar os/as dados/informações de forma conjunta e identificar padrões comuns e (ou) estruturados e (ou) hierarquizados, tomando-se os critérios avaliativos considerados na elaboração das AE pelos professores, as informações obtidas e categorizadas foram, então, convertidas em dados binários, atribuindo-se o dígito "1" para as respostas positivas, e "0" para as negativas, em relação às questões constantes do roteiro de avaliação utilizado (Quadro 1).

A dissimilaridade entre as atividades avaliativas analisadas foi estimada com base no coeficiente de Jaccard, utilizando-se o software DARwin v6.0.014 (PERRIER; JACQUEMOUD-COLLET, 2016). A relação de dissimilaridade foi avaliada com o auxílio de um dendrograma construído com base no método de agrupamento de UPGMA, usando o software MEGA 5.05 (TAMURA et al., 2011). A qualidade gráfica do dendrograma foi estimada pelo coeficiente de correlação cofenética e seu ajuste de acordo com o teste de Mantel para 9999 permutações. A decomposição da variação dentro e entre os professores foi realizada com base na AMOVA, usando o software GenAlex v6.5 (PEAKALL; SMOUSE, 2012), com 9999 permutações.

\section{Resultados e discussão}

Por meio da matriz de dados construída, gerou-se o dendograma apresentado na Figura 1, no qual nota-se o estabelecimento de oito agrupamentos categoriais (AC) distintos de AE, hierarquizados por características similares. 


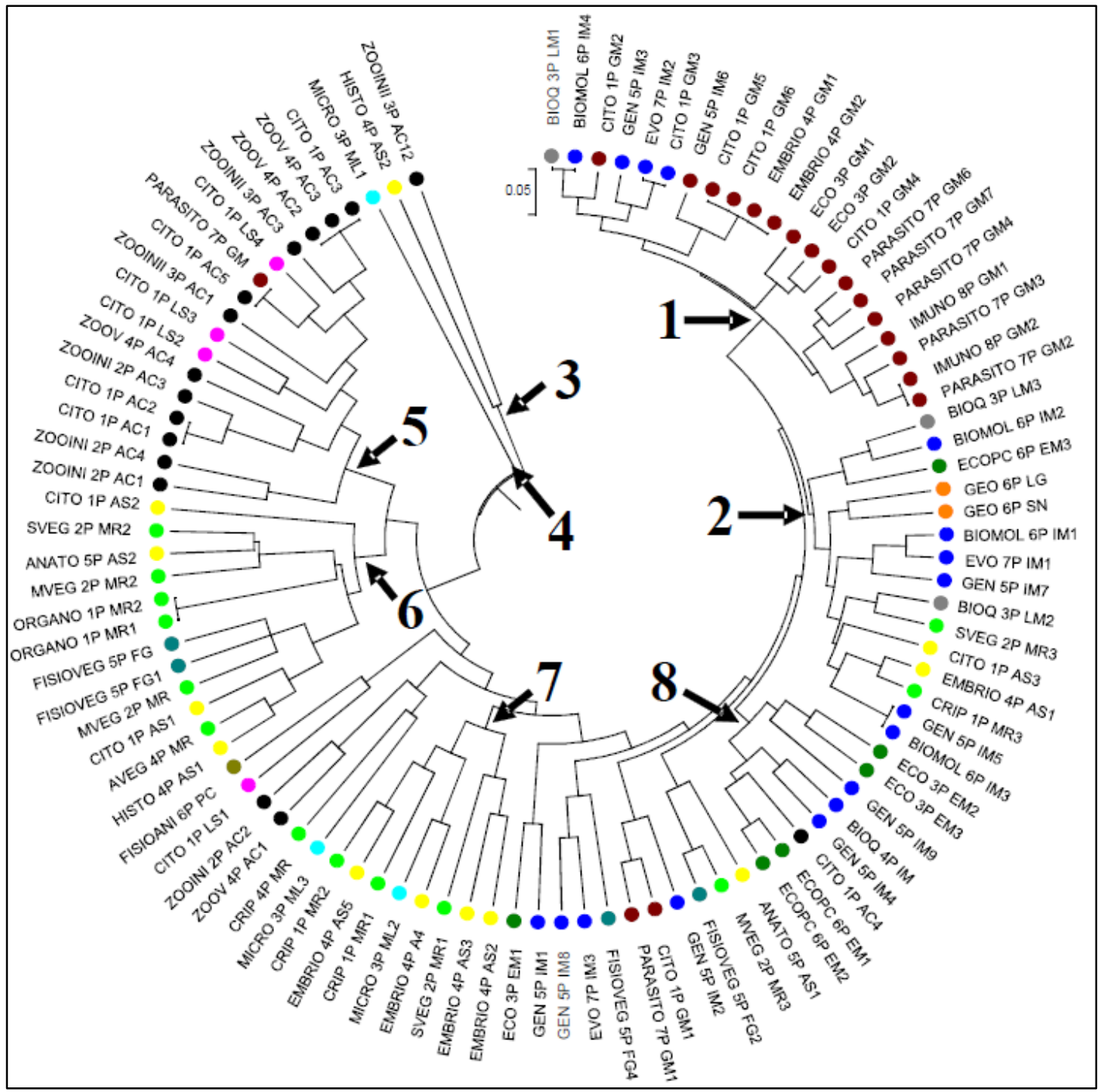

Figura 1: Relação de dissimilaridade entre as $100 \mathrm{AE}$ avaliadas neste estudo, obtida à luz do coeficiente de Jaccard.

Fonte: Elaborada pelos autores (2017)

Como exemplares são apresentados, neste artigo, alguns dos oito AC. O AC1 é estruturado por 21 provas (21\% das AE analisadas), sendo elas constituídas basicamente por local para a identificação do estudante, e por questões discursivas, porém sem apelo à "memorização". Abrangem, ainda, a colocação de textos em situações reais do cotidiano do estudante (Figura 2A) que, consequentemente, aproxima o estudante dos conceitos trabalhados em sala de aula, contribuindo com a sua aprendizagem. Quanto aos tipos de perguntas, esse grupo é constituído de $\mathrm{AE}$ que exigem domínio de linguagem, compreensão de fenômenos biológicos (Figura 2B) e solução de problemas. Além disso, essas AE são do tipo análise (Figura 2C), reconhecimento e compreensão. A Figura 2 apresenta alguns exemplos de questões que foram enquadradas juntas, as quais são representativas do perfil deste grupo. 


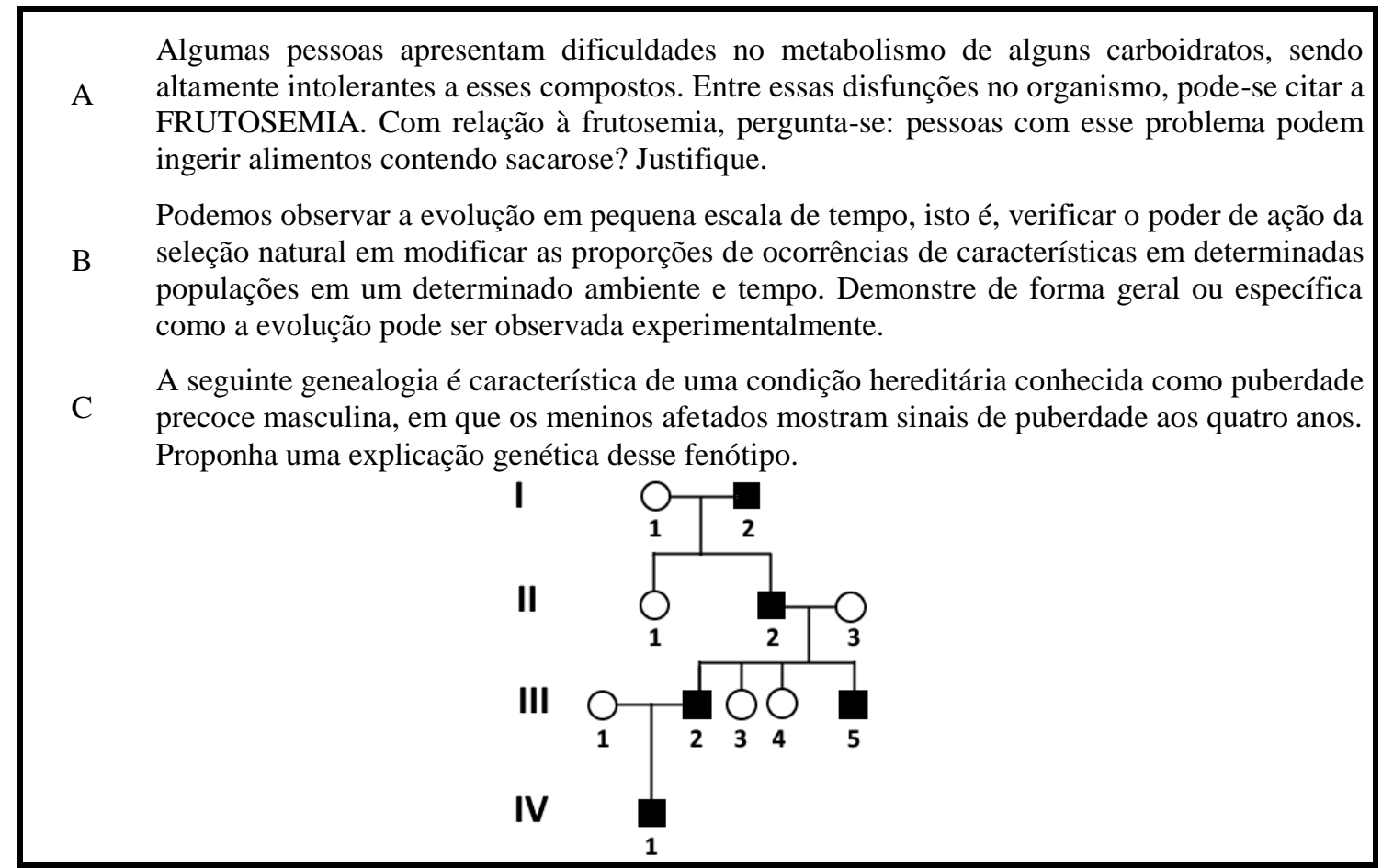

Figura 2: Exemplos de questões de AE enquadradas no AC 1. (A) questão retirada de uma AE de Bioquímica (LM); (B) Questão retirada de uma prova de Evolução (IM2) e (C) questão retirada de uma prova de Genética (IM3)

Fonte: Elaborada pelos autores (2017)

Sobre estes dados, destacam-se os tipos de questões semelhantes à exemplificada na Figura 2A, muito presentes no AC1, as quais contemplam o cotidiano do estudante, o que torna viabiliza o processo de ensinagem-aprendizagem, já que, para os estudantes não faz sentido aprender determinados conceitos científicos deslocados de significados e(ou) da realidade dos estudantes, no sentido de não favorecer a formação crítica. Nesse sentido, Freire (2011) salienta que, o professor que busca contextualizar o conteúdo à realidade do aluno, consegue resultados satisfatórios no processo de ensino-aprendizagem. Este autor enfatiza o papel do professor de instigar o aluno a questionar, a buscar novos conhecimentos, proporcionando um conflito cognitivo entre o conhecimento prévio e o cientifico fazendo, assim, a evolução da curiosidade ingênua para a epistemológica.

Além disso, vale salientar que as AE do AC1 supracitado contemplam abordagens qualitativas, no sentido de apresentar exigências que transcendam a simples e pura memorização de conceitos (sem aplicação dos conteúdos memorizados), o que aponta para AE que auxiliam no processo de "ensinagem" e de aprendizagem.

O AC2 é formado por 15 provas (15\%) em que as questões não demonstraram orientação para o estudante realizar a $\mathrm{AE}$ que, em sua maioria, foram constituídas de 
questões do tipo reconhecimento e compreensão, não apresentando perguntas classificadas como síntese e julgamento. Além disso, esse AC é constituído essencialmente de questões que exigem do estudante a capacidade de apenas memorizar conceitos que, conforme a Figura 3, representam o perfil das AE desse AC.

Sobre avaliações que exigem que o estudante seja capaz apenas de decorar os conteúdos, Mizukami (1986) explana que essas são realizadas com o intuito de reproduzir o conteúdo trabalhado em sala de aula. Comenta ainda que por meio delas, destacam-se a quantidade e exatidão que o estudante consegue reproduzir.

Conforme Soistak e Pinheiro (2009), a memória basicamente é um processo de estocar informações, essencial para a aprendizagem, não servindo para ser utilizada em apenas um momento.

Nesse contexto, a crítica não se refere às $\mathrm{AE}$ ou questões que exigem memorização de conteúdos, mas sim àquelas em que a capacidade de memorizar conceitos não é explorada de forma contextualizada ou problematizada.

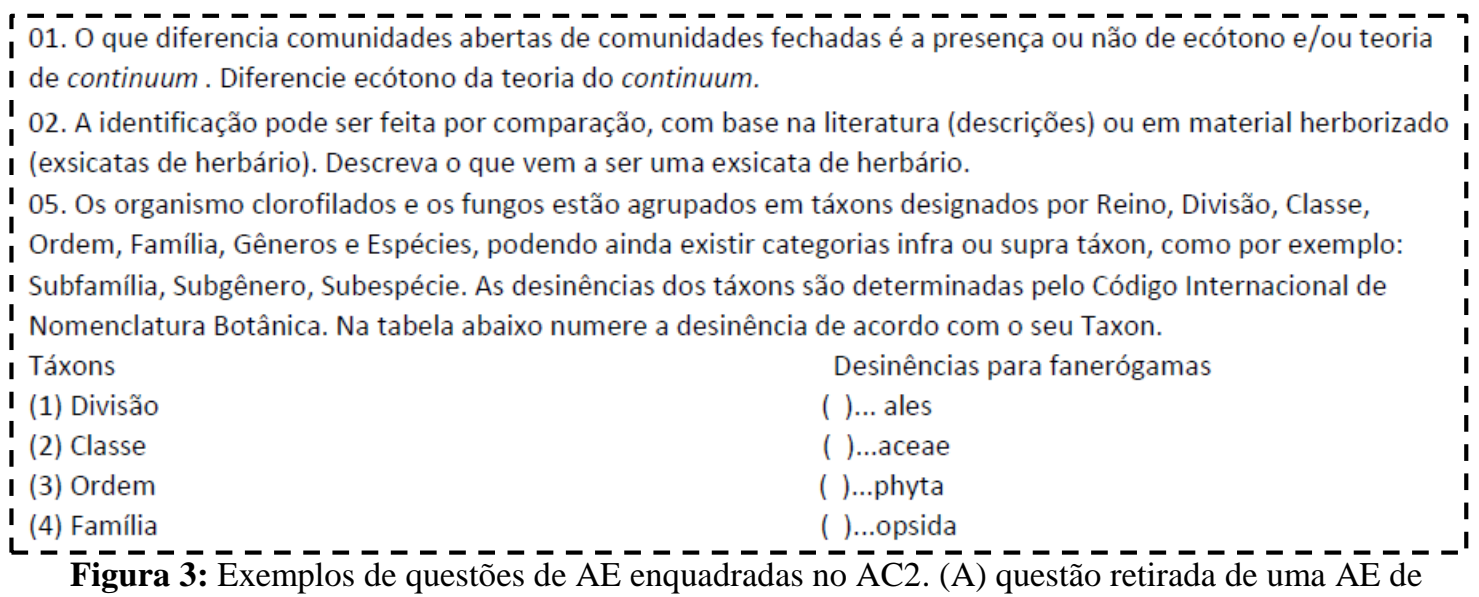
Ecologia de População e Comunidade (EM3); (B) e (C) Questões retiradas de uma AE de Sistemática Vegetal (MR3)

Fonte: Elaborada pelos autores (2017)

O AC3 é composto por apenas $2 \mathrm{AE}(2 \%)$, em que a constituição dessas AE é por questões do tipo objetivas (Figura 4A e 4B), além de não exigirem do estudante domínio de linguagem, compreensão de fenômenos, tampouco construção da argumentação. Em suma, tais AE apresentam apenas questões do tipo reconhecimento e compreensão. A Figura 4 apresenta alguns exemplares de questões desse AC3 de AE. 


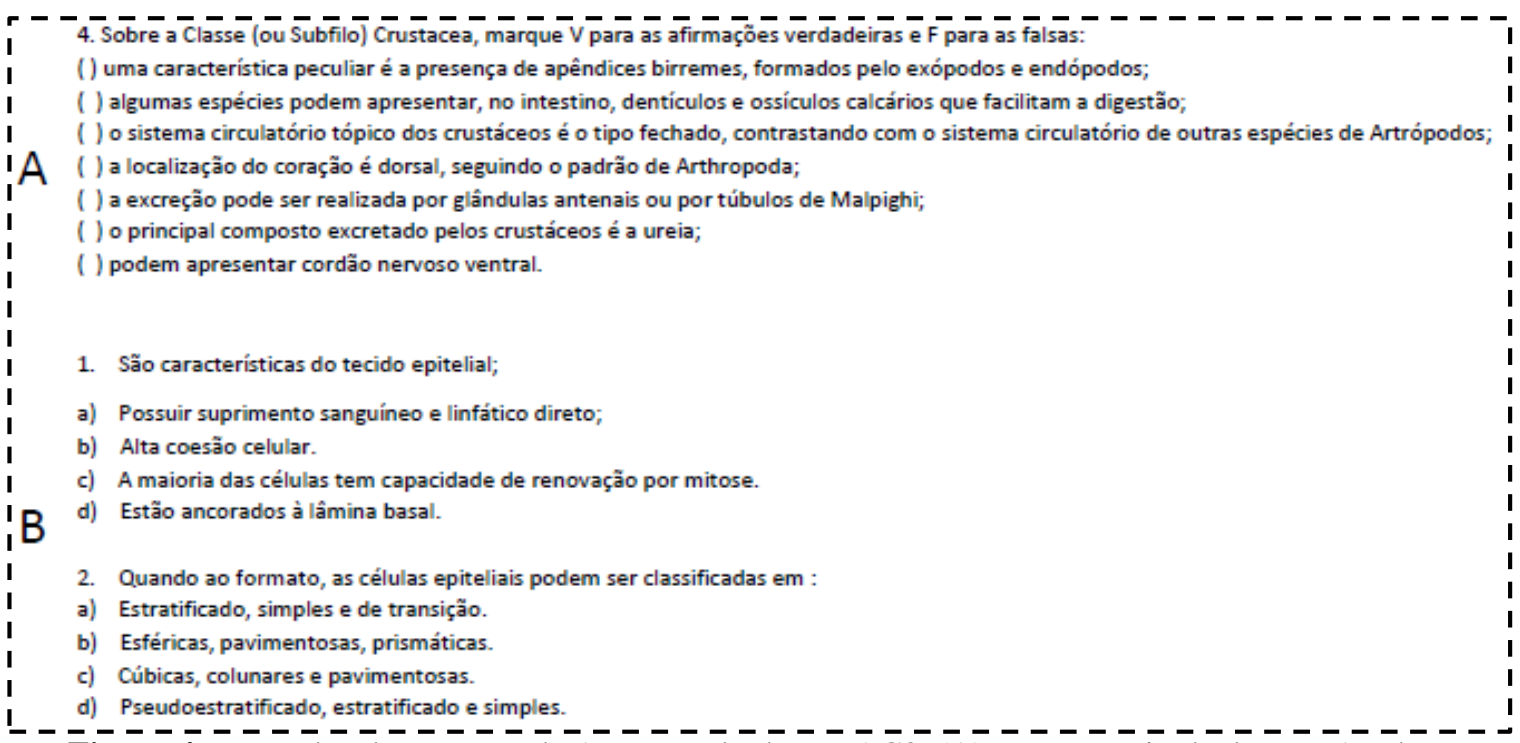

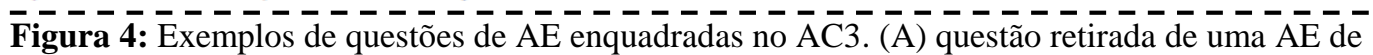
Histologia (AS2); (B) Questão retirada de uma AE de Zoologia de Invertebrados II (AC12)

Fonte: Elaborada pelos autores (2017)

Em outros AC foi possível observar que, independente do formato das questões (objetivas ou discursivas), as AE não exigem habilidades mais complexas como, por exemplo, a de comparar e compreender fenômenos biológicos. A ausência de problematização serve apenas para averiguar se o estudante sabe ou não reproduzir o conceito científico memorizado, o que é criticado por Romão (2008).

Pode-se perceber que entre as AE analisadas, das diferentes disciplinas, ainda que ministradas pelos mesmos docentes, em sua maioria, não há um padrão; o que parece sugerir que os professores mudam o estilo de AE, a depender da disciplina ofertada por eles. A decomposição da variação dentro da disciplina e entre os professores, realizada com base na AMOVA, sinaliza que $71 \%$ da variação existente entre as AE se dá entre as $\mathrm{AE}$, elaboradas pelo mesmo docente; e não [ao contrário do que se possa imaginar] entre professores diferentes.

Tabela 2: Categorização das AE em "formativa" ou "tradicional", de acordo com os AC.

\begin{tabular}{ll}
\hline Categoria de AE & Agrupamento categorial (AC) \\
\hline Formativa & 01 \\
Tradicional & $02,03,0405,06,07$ e 08 \\
\hline
\end{tabular}

Fonte: Elaborado pelos autores.

Entre as subcategorias de avaliações por AC, em maior número há aquelas que foram categorizadas como tradicionais, como é possível depreender da Tabela 2. 


\section{Considerações finais}

A análise de todas as $\mathrm{AE}$ da amostra permite inferir que as $\mathrm{AE}$ são predominantemente tracionais, e que este resultado pode estar associado à modalidade de formação dos professores [bacharéis e licenciados], devidamente mapeados no levantamento realizado.

O papel da avaliação vai muito além da mera classificação. Ela deve servir para além da simples coleta de informações acerca dos conceitos científicos apreendidos pelos educandos, também se presta a avaliar as práticas pedagógicas dos professores.

Face a todo exposto, propõe-se o (re)pensar nas formas de planejar, elaborar e aplicar as avaliações, sobretudo pelo fato de, em geral, serem travestidas de elementos constitutivos dos processos de "ensinagem" e de aprendizagem.

O estudo sinaliza problemas nos agrupamentos categoriais hierárquicos e aponta para a necessidade de reflexões acerca do avaliar, não como um fim e(ou) momento único, mas como um meio para apontar possíveis caminhos alternativos rumo à melhora desse processo. A classificação pela classificação dos alunos, não contribui para avanços nessa discussão.

\section{Referências}

ARREDONDO, S. C.; DIAGO, J. C. Avaliação educacional e promoção escolar. Trad. Sandra Martha Dolinsky. Curitiba: Ibpex; São Paulo: Unesp, 2009.

CAMPOS, R. I.; GOMES, I. C. P.; FURTADO, W. W. Avaliação da aprendizagem no ensino de Física: um olhar sobre as concepções dos professores licenciados em Física da cidade de Inhumas, GO. Revista Polyphonía, Goiânia, v. 23, n. 1, p. 71-81, jan./jul. 2012. Disponível em: <http://www.revistas.ufg.br/sv/article/view/26690>. Acesso em: 10 nov. 2016.

COLL, C.; MARTÍN, E.; ONRUBIA, J. A avaliação da aprendizagem escolar: dimensões psicológicas, pedagógicas e sociais. In: COLL, C.; MARCHESI, A.; PALACIOS, J.

Desenvolvimento psicológico e educação. Psicologia da educação escolar. 2.ed. Porto Alegre: Artmed, 2004. p. 370-385.

FERNANDES-SOBRINHO, M. et al. Avaliações aplicadas em uma Licenciatura em Ciências Biológicas: dos agrupamentos categoriais hierárquicos a caminhos alternativos. In: CONGRESSO IBERO-AMERICANO EM INVESTIGAÇÃO QUALITATIVA, 6, 2017, Salamanca. Anais... Salamanca: Ludomedia. v. 1. p. 640-649, 2017. Disponível em: <http://proceedings.ciaiq.org/index.php/ciaiq2017/article/view/1373/1330>. Acesso em: 19 fev. 2018.

FREIRE, P. Pedagogia da autonomia: saberes necessários à prática educativa. 43. ed. São Paulo: Paz e Terra, 2011. 
GARUTTI, S. Discutindo avaliação formativa nas disciplinas de Ciências e Biologia. Revista Uniandrade, Curitiba, v. 11, n. 1, p. 37-52, jan./jun. 2010. Disponível em:

<http://www.uniandrade.br/revistauniandrade/index.php/revistauniandrade/article/view/3>. Acesso em: 10 set 2016.

GUERRA, M.Á. S. La evaluación: un proceso de diálogo, comprensión y mejora. Revista Investigación en la Escuela, Granada, n. 20, p. 23-35, 1993

HAYDT, R. C. Avaliação do processo ensino-aprendizagem. 6. ed. São Paulo: Ática, 2008.

HOFFMANN, J. Avaliação mediadora: uma prática em construção. 33. ed. Porto Alegre: Mediação, 2014.

LUCKESI, C. C. Avaliação da aprendizagem escolar: estudos e proposições. 22. ed. São Paulo: Cortez editora, 2014.

MIZUKAMI, M. DA G. N. Ensino: as abordagens do processo. São Paulo: Editora Pedagógica e Universitária, 1986.

PEAKALL, R.; SMOUSE, P. E. GenAlEx 6.5: genetic analysis in Excel. Population genetic software for teaching and research--an update. Bioinformatics, Oxford, v. 28, n. 19, p. 25372539, Oct. 2012.

PERRENOUD, P. Avaliação: da excelência à regulação das aprendizagens. Entre duas lógicas 1. ed. Belo Horizonte: Artmed, 1999.

PERRIER, X.; JACQUEMOUD-COLLET, J.-P. DARwin. Dissimilarity, Analysis and Representation for Wildows (Versão 6.0.014), 2016. Recuperado de http://darwin.cirad.fr/

ROMÃO, J. E. Avaliação, Diálogo, Desafios e Perspectivas. 7 ed. São Paulo: Cortez editora, 2008.

SANT’ANNA, I. M. Por que avaliar? Como avaliar? Critérios e instrumentos. 17. ed. Petrópolis: Vozes, 2014.

SANTIAGO, E. Trabalho Pedagógico e Avaliação Educacional. In: NETO, J. B.; SANTIAGO, E. (Org.). Formação de professores e prática pedagógica. 1ed. Recife: Massangana, v. 1, p. 121-129. 2006.

SOISTAK, M. M; PINHEIRO, N. A. M. Memorização: atual ou ultrapassada no ensinoaprendizagem da matemática? In: SIMPÓSIO NACIONAL DE ENSINO DE CIÊNCIAS E TECNOLOGIAS, 1, 2009, Ponta Grossa. Anais... Ponta Grossa: UTFPR, 2009. p. 971-983.

TAMURA, K. et al. MEGA5: Molecular Evolutionary Genetics Analysis Using Maximum Likelihood, Evolutionary Distance, and Maximum Parsimony Methods. Molecular Biology and Evolution, Rockville, 28, n. 10, p. 2731-2739, Oct. 2011.

Recebido em: 24 de março de 2018.

Aceito em: 05 de abril de 2018. 